and vice chair of BRC with terms that began in June. We are thrilled to welcome Dr Peter Seidenberg as our new Steering Committee Chair and Dr Navkiran Shokar as our Vice Chair and look forward to tapping into their experience and leadership to guide the committee as BRC moves to its next phase. We additionally want to thank Dr Bernard Ewigman for his $6+$ years of service creating, leading, and guiding the BRC Initiative and the Steering Committee. His vision and leadership have driven this effort from the first day, and we so appreciate his investment and his continued willingness to serve as a mentor and resource to our team. We will continue to build out succession plans for committee members as another step in this program's evolution and maturation.

\section{The New BRC Fellowship}

In 2021 we are also launching the new BRC Fellowship. The purpose of the BRC Fellowship is to equip individuals with the knowledge, leadership skills, mentorship, and peer support to develop and implement a strategic plan for building research capacity within their own programs, departments, or institutions. Fellows might be chairs, aspiring chairs, research directors, research change agents in a residency program, administrators, or others charged with making change in the organization. BRC fellows display skills in leadership, research organization, and faculty development. Candidates will be change agents for building their organization's capacity for producing scholarly activity. The fellow's organization should support development of that capability, including supporting the development of a strategic plan as a product of the BRC Fellowship.

The inaugural cohort of BRC fellows will begin in conjunction with the 2021 NAPCRG Annual Conference. We encourage all who may be interested to learn more here: https://adfm.org/programs/ building-research-capacity-fellowship/.

\section{BRC Resources \& Consultation}

As a main part of its mission and efforts, BRC continues to offer resources and consultation services to all departments and residency programs. BRC Consultations range in scope, helping departments and residency programs to enhance and expand scholarly activity, from evaluation and improvement of educational and clinical programs to increasing capacity to compete for external grant funding. Initial exploratory discussions are held at no charge and more in-depth consultations are tailored to individual client goals and needs. Consultations may be short term or longitudinal and can include bringing one of the consultants on-site in person or may be conducted entirely virtually. If you are interested in learning more about a BRC consultation for your department or residency program, please contact Jessie Vera, ADFM Program \& Communication Coordinator at jvera@adfm.org.

Peter Seidenberg, Navkiran Shokar, Jessie Vera, Amanda Weidner and Julie Sutter, The BRC Steering Committee

\section{References}

1. Ewigman B, Davis $A$, Vansaghi $T$, et al. Building research $\varepsilon$ scholarship capacity in departments of family medicine: a new joint ADFM-NAPCRG initiative. Ann Fam Med. 2016;14(1):82-83. https:// www.annfammed.org/content/14/6/585

2. Weidner A, Peterson LE, Mainous AG 3rd, Datta A, Ewigman B. The current state of research capacity in US family medicine departments. Fam Med. 2019;51(2):112-119.

3. Mullen R, Weidner A, Liaw W, Mainous AG, Hester C, GoodyearSmith F, Nease D, Schneider FD, Ewigman B. Family medicine research capacity in the USA. Family Practice. 2021;38(2):186-188. https://doi.org/10.1093/fampra/cmaa119

4. Liaw W, Eden A, Coffman M, Nagaraj M, Bazemore A. Factors associated with successful research departments a qualitative analysis of family medicine research bright spots. Fam Med. 2019;51(2):87-102.

5. Liaw W, Petterson S, Jiang V, Bazemore A, Pecsok J, McCorry D, Ewigman B. The scholarly output of faculty in family medicine departments. Fam Med. 2019;51(2):103-111.

6. Liaw W, Bazemore AW, Ewigman B, Turin TC, McCorry D, Petterson S, Dovey SM. Advancing bibliometric assessment of research productivity: an analysis of US Departments of Family Medicine. J Prim Health Care. 2020;12(2):149-158.

7. Weidner A, Peterson LE, Mainous AG, Ewigman B. Attitudes and Perceptions of research among US family medicine department chairs. Fam Med. 2021; 53(2):98-103.
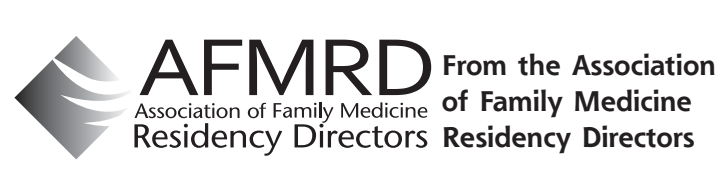

Ann Fam Med 2021;19:472-473. https://doi.org/10.1370/afm.2745.

\section{FAMILY MEDICINE PROGRAMS MEETING THEIR COMMUNITY NEEDS: LESSONS LEARNED FROM COMMUNITY-BASED PROGRAM COVID-19 RESPONSE}

\section{Introduction}

COVID-19 has changed the way we all live and work, but how things changed depended quite a bit on your local community. Little has been written about the response of family medicine programs in smaller communities, while the heroic efforts undertaken in large academic medical centers have been well-documented. Full-spectrum family physicians had to respond by providing medical care not just in the hospital setting but also across the many settings where they work and 
engage with their communities. Many of our programs have important stories to tell $l_{i}$ this is the story of our community.

The Lawrence Family Medicine residency is a community-based teaching health center program affiliated with a community hospital in a city of 85,000 people located about 25 miles north of Boston. Our community is one of the poorest in New England and has the largest Latinx (almost 80\%) population in Massachusetts. Racial and ethnic health disparities were magnified by COVID-19 and the community was one of those hit hardest in New England $i$ 80\% of hospitalized patients in spring 2020 had COVID-19. Residents and faculty of the residency program worked together across their full spectrum of family medicine skills to provide care to our community.

\section{Addressing the Emerging Pandemic on the Streets}

Across the country, efforts to care for the homeless during COVID-19 largely fell on individual communities. Shelters were overcrowded with limited supplies, unsheltered individuals had no daytime respite, and access to food and hygiene became significantly reduced. Our team in Lawrence initiated a weekly video conference to bring homeless organizations together. Within weeks, our audience included local legislators, state organizers from the Federal Emergency Management Agency (FEMA), several regional mayoral offices, health care providers (including our regional hospital and Mayor's Health Task Force), food pantries, our community action council, and local police and fire departments. This collaboration allowed us to continue medical services (both in person and virtually), supply protective equipment to shelters, offer immediate access to COVID-19 testing, provide "pop-up" vaccine clinics and education, and establish 2 regional hotels for shelter depopulation and access for the unsheltered.

\section{Meeting the Needs of Patients in a Community Hospital}

Lawrence residents and faculty were involved in almost every aspect of care during the COVID-19 surge at our community hospital. Given the dramatic upswing in critically ill cases and the lack of transfer ability to overburdened tertiary care centers in Boston, our hospital expanded its ICU capacity by adding 12 beds in the PACU staffed primarily by our family medicine attending physicians and residents. The 32-bed COVID-19 unit, with capacity for high-flow oxygen treatment, was staffed solely by our attendings and residents from late April to mid-June 2020. A small group of our faculty staffed a COVID-19 treatment team that designed the policies and algorithms for management of COVID-19 patients, personal protective equipment (PPE), and the procedures allowing de-escalation of PPE for patients under investigation for COVID-19.

\section{Helping People Scared at Home-Rapid Transition to Telehealth and Telehealth COVID-19 Care}

Our clinic made a rapid transition from $100 \%$ in person to nearly $100 \%$ telehealth visits within a week. The residents who were not assigned in the hospital had their outpatient clinics converted to telehealth with precepting via Zoom. From March through June 30, 2020, residents conducted over 10,000 telehealth visits-helping our health center expand its capacity to meet the increased needs of patients. Patients with suspicious symptoms or who tested positive for COVID-19 were enrolled in a remote monitoring protocol where they measured their temperature and pulse oximetry at home and had daily telehealth visits with nurses and clinicians.

\section{Getting Vaccines to the People Who Need It Most}

The history of how medical institutions have interacted with communities of color and the overwhelming health inequities that worsened during the pandemic contributed significantly to vaccine hesitancy in our community. Through outreach and a consistent presence at virtual community meetings, our faculty and residents arranged multiple in-person and virtual events at various organizations to increase vaccine awareness, dispel myths, and empower individuals to make educated decisions about the COVID-19 vaccine. Our clinic undertook the massive task of implementing central vaccine sites and mobile vaccine clinics at shelters, rooming houses, and other community organizations across the city.

\section{Conclusion}

Many community-based family physicians have similar but unique stories. We need to record them or write them down now-before we forget. As we watched family physicians work together across their full spectrum of family medicine skills to provide care to our community, we realized that our broad skill set is unique to our training and cause for celebration and praise.

Wendy B. Barr, MD, MPH, MSCE, Jennifer Somers, $M D_{i}$ Ryan Dono, MD, Joshua St. Lonis, MD, MPH, Lawrence Family Medicine Residency, Greater Lawrence Family Health Center, Lawrence, MA, Tufts University School of Medicine, Boston, MA 